\title{
PREDICTING PUMPS AND FANS EFFICIENCY USING DECENTRALIZING TECHNIQUE IN NON-INDUSTRIAL BUILDINGS
}

\author{
DR. KAMAL KISHORE PATHAK \\ Department of Mechanical Engineering, Government Polytechnic Sheikhpura, Bihar
}

\begin{abstract}
Almost $42 \%$ of the chief energy is being used by the non-industrial buildings. So, to meet the energy challenges, it is essential to reduce the non-industrial buildings consumption. Pump and fan operations in these buildings use a remarkable amount of energy. Therefore, this paper mainly deals with finding ways for reducing fan and pump energy consumptions and increasing their respective efficiency in buildings sector. The advantages of using decentralized fan and pump systems has also been studied. Overall an energy efficient system is developed using this technique.

KEYWORDS: Decentralized Systems, Energy Efficient
\end{abstract}

Received: Jun 06, 2020; Accepted: Jun 26, 2020; Published: Aug 25, 2020; Paper Id.: IJMPERDJUN2020881

\section{INTRODUCTION}

The increasing comfortable residential living along with lighting and space conditioning has been successfully provided by the energy sources. The reduction of utilization of power for these appliances will not only reduce the energy consumption but also it's associated environmental effect. In buildings particularly non-industrial, ventilation, heating, lighting, appliances (refrigerators, fans, dryers), electronics items, and air conditioning consumes major portion of the energy. For each of these apparatus there are opportunities for controlling the systems and improving its performance. The systems can be controlled by its proper designing so that the sensors can adjust light levels to availability and uses, on the other hand performance of the system can be improved by improving its efficiency.

In a building, energy use depends on energy systems design and its effective operation and maintenance. Buildings can be considered as integrated and interrelated systems. Also different climates probably need different equipment and designs, for example lighting depends on the efficiency of the devices that transform electricity to visible light, \& on other lighting controls, so as lighting controls have a reduced net affect on energy use as the light fixture performance is increased, and same is the case with other appliances [1].

In many applications pumps are used in cooling and heating systems. The pumps have often long operational hours along with poor efficiency which results in significant energy use. One other appliance used for ventilation systems are fans. Fans are mostly situated in an air handling unit such as air cooler and heat exchanger [2]. So, if we can control pump and fan system in buildings, there is a scope of energy savings in buildings. In this paper, hence, our purpose is to find the means so as to increase the efficiency of pumps and fans in building in order to reduce energy consumptions. This paper starts with, followed by, further and finally the conclusion. 


\section{INCENTIVES FOR IMPROVED FAN EFFICIENCY AND FAN SYSTEM EFFICIENCY Pumps and Fans}

The pump is centrally located in most of the heating \& cooling systems. Its flow rate is controlled by control valves and balancing valves. In a system, the pressure drop of these valves is a main part of the total pressure drop and causes energy losses. So the pump work can be saved if the valves will be removed. The performance of pump depends on the motor efficiency, hydraulic efficiency and the efficiency of frequency converter. The expected saving potential of a pump may be affected by pump speed, Losses in motor etc. Efficiency is also affected by oversized motors. Motor efficiency also depends on rated load [3][4].

Fans basically consist of multiple rotating blades powered by a motor. They are used to move air in a variety of common residential applications, for example refrigerator, central cooling and heating and ceiling fan. There are 2 types of fans: axial \& centrifugal fans. The application implies which type of fan is preferable based on requirements for size, air flow, space, pressure increase and overall cost.

Almost $24 \%$ of the electrical energy use for motors which corresponds to about $9 \%$ of the total electrical energy is utilized for fan. The knowledge and available statistics about energy use for pumps and fans in residential buildings are limited. In this reaerch, we will try to save potential of electrical energy for pumps and fans in buildings, particularly nonindustrial. We will also try to present the different approach and measures for reducing energy needs in buildings without making any sacrifice in comfort levels.

\section{ENERGY EFFICIENCY OF A BUILDING}

In a building, the energy efficiency is defined as the extent to which the energy consumption per meter square of floor area to established energy consumption for that particular type of building under defined climatic conditions [5].

The main target of energy efficiency steps is to reduce the amount of energy consumed while improving the quality of services available in the building. Reduction of electricity use for domestic type appliances and by reducing energy use for heating and cooling can results into energy efficient system.

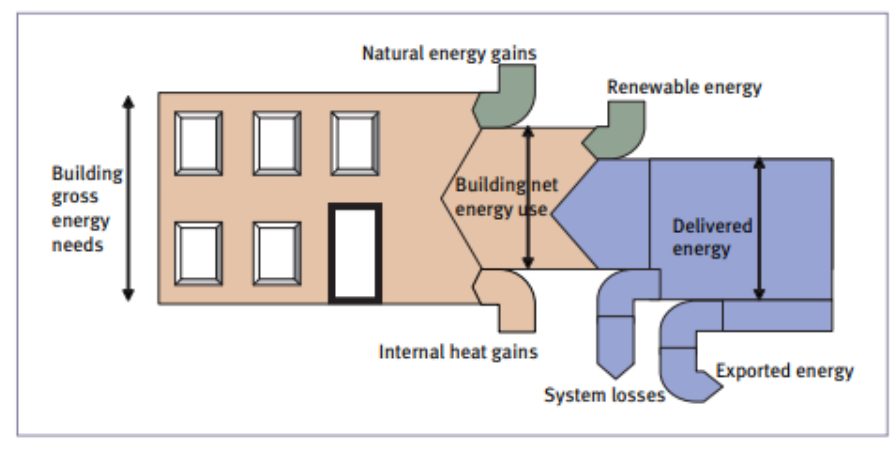

Figure 1: Energy Flows in a Building.

Figure 1, depicts the energy flows in a building. The gross energy needs of a building represent its anticipated requirements for lighting, ventilation, heating/cooling and air conditioning. The delivered energy, internal heat gains and natural energy gains all contribute to providing the energy requirements of a non-industrial building [6][7][8][9][10]. 
The SFP (specific fan power), and the SPP (specific pump power), can be obtained by following equations:

$$
\begin{aligned}
& S F P=\frac{\sum \dot{W}_{\text {fan }}}{\dot{V}_{\text {max }}} \\
& S P P=\frac{\sum \dot{W}_{\text {pump }}}{\dot{V}_{\text {max }}} \\
& S F P=\sum \frac{\Delta p_{\text {fan }}}{\eta_{\text {fan }}} \\
& S P P=\frac{\Delta p_{\text {pump }}}{\eta_{\text {pump }}}
\end{aligned}
$$

These parameters quantify the energy efficiency of the distribution system including the fan and pump respectively. Hence, these parameters are very useful and are needed in the design process. Here, we will apply this formula to obtain efficiency for decentralized system, both pumps and fans.

\section{DECENTRALIZATION TECHNIQUE}

The energy efficiency of a pumping system depends on both its design and operation. So to improve the operating efficiency of a pump installed in non-industrial building for energy conservation, it is required to obtain a tradeoff between pump design and operation. In this research, we try to analyze the approach of decentralization of pump for reducing energy consumption. Figure 4 shows a decentralized system.

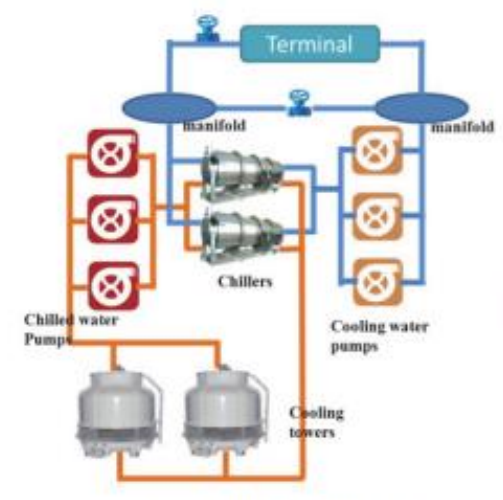

(a) Structure of the physical system

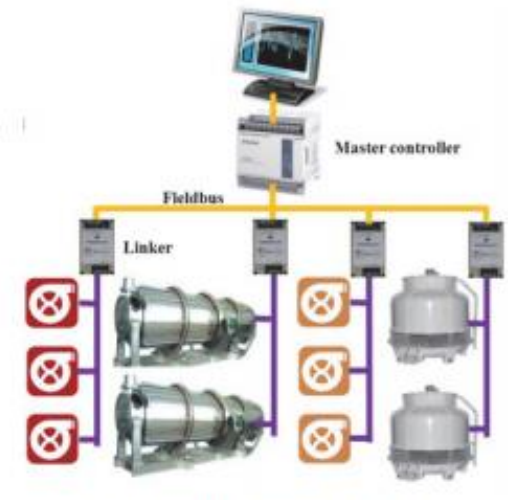

(b) Structure of the centralized control system

Figure 2: Decentralized Pump.

In this approach, for circulating and regulating flow in a pump system, we do not require the central pumps distribution pumps, balancing valves, and modulating control valves. Instead of that we used Decentralized pumps with variable speed drivers situated at cooling/heating coils, which is used to flow \& guide liquid through the coils, main return line and main supply line. It is found that without the balancing valves and control valves, pressure drops will be less.

The similar decentralized technique we can apply on the fan system/ ventilation system. Figure shows fan decentralization technique. 


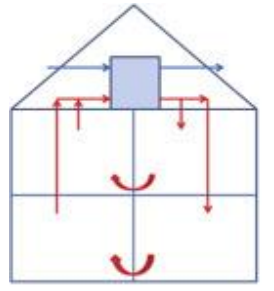

Centralized

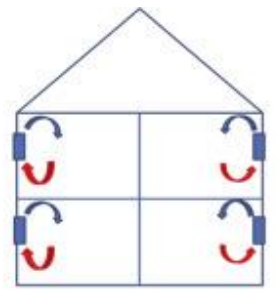

Single Room Unit

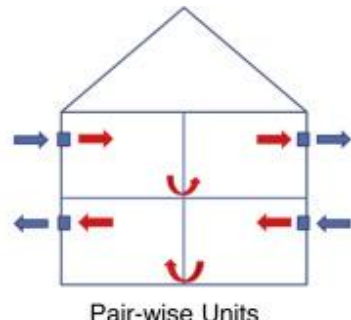

Pair-wise Units

Figure 3: Decentralized Fans.

The centralized fan/ventilation systems utilize a ductwork to extract air and transport its supply, where as in decentralized fan systems the device is equipped with fans and heat exchanger and fans, and are situated in the front of the building.

The prime advantages of using decentralized fan system are as follow:

- It takes up less space than the central fan systems.

- It normally does not require additional fire protection costs

- It is possible to make a stepwise replacement of the old ventilation systems, this can definately reduce the cost

- $\quad$ Easier individual control of separate spaces

Now, for obtaining the system efficiency for a decentralized system, we would specific pump power SPP, and specific fan power SFP. The figure.4 illustrates relative specific fan and pump power for different system efficiencies at different pressure drops.

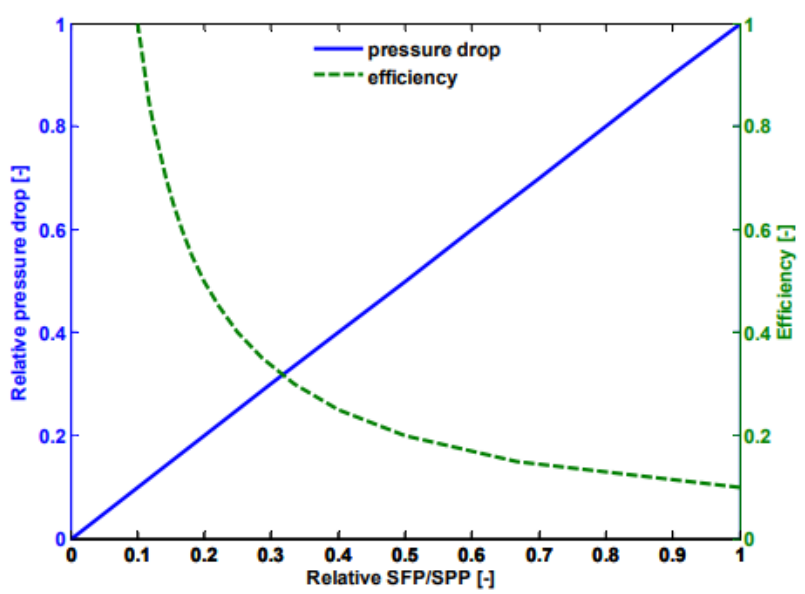

Figure 4: Relative SFP/SPP with Efficiency.

Now, in order to double the pump/fan, the system pressure drop should be halved. The figure clearly indicate that an equal relative change in efficiency and pressure drop gives a large saving for the efficiency change as long as the absolute value of the slope of efficiency curve is flatter than that of the pressure curve.

\section{CONCLUSIONS}

In this research, we tried to obtain an approach which can reduce non-industrial buildings consumption. This reduce energy consumption has lots of environment significance. Here, we analyzed the consumption power of fan and pump installed in residential building and suggested a method for reducing pump and fan energy consumption using decentralized technique. 
This paper also discussed through graph relative specific fan and pump power for different system efficiencies at different pressure drops Overall, an energy efficient system is developed using this decentralized technique. Our future work may include modeling and simulation of this system and also to apply this decentralization technique to other appliances.

\section{REFERENCES}

1. Bernier, M A, Bourret, B, 1999. Pumping energy and variable frequency drives. ASHRAE Journal, vol. 41, no. 12, December, pp. 37-40. (Amer. Soc. Heating, Ref. Air-Conditoning Eng. Inc.) Atlanta.

2. Carlson, R, 2000. Correct method of calculating energy savings to justify adjustable-frequency drives on pumps. IEEE Transactions on Industry Applications, vol. v 36, no. $n$ 6, Nov, pp. p 1725-1733. (Institute of Electrical and Electronics Engineers Inc.) Piscataway, NJ, USA.

3. Paarporn, Somchai. "Decentralized pumping system." U.S. Patent 6,607,141, issued August 19, 2003.

4. Wang, Shi-Qiang, Jian-Chun Xing, Zi-Yan Jiang, and Yun-Chuang Dai. "Decentralized Optimization Algorithms for Variable Speed Pumps Operation Based on Local Interaction Game." Journal of Control Science and Engineering 2018 (2018).

5. Moynihan, Gary P., and Frank L. Barringer. "Energy Efficiency in Manufacturing Facilities: Assessment, Analysis and Implementation." Energy Efficient Buildings (2017): 127.

6. Schild, P. G., and M. Mysen. "Recommendations on specific fan power and fan system efficiency." Technical Note AIVC 65 (2009).

7. Wang, Chong, Qun Sun, and Limin Xu. "Development of an integrated cooling system controller for hybrid electric vehicles." Journal of Electrical and Computer Engineering 2017 (2017).

8. Monroe, Robert C. "Improving cooling tower fan system efficiencies." In Proceedings of the 7th Turbomachinery Symposium. Texas A\&M University. Gas Turbine Laboratories, 1978.

9. Koor, M., Anatoli Vassiljev, and Tiit Koppel. "Optimization of pump efficiencies with different pumps characteristics working in parallel mode." Advances in Engineering Software 101 (2016): 69-76.

10. Hydraulic Institute, Europump, Department of Energy, 2004. Variable speed pumping A guide to successful applications, Executive summary. pp. 15.

11. Tien-Chin Wang \& Hsiu-Chin Hsieh, "An Analysis of School-Based Curriculum Development: The Taiwanese School of Melbourne ", International Journal of Business and General Management (IJBGM), Vol. 6, Issue 1,pp. 17-24

12. Kwabena Owusu \& Ernest Kingsley Enyan, "The Role of Internal Auditing Function in Corporate Governance in a Decentralized Government System: The Case of Ghana ", IMPACT: International Journal of Research in Business Management (IMPACT: IJRBM), Vol. 7, Issue 3, pp. 15-30

13. Smt. M. Suma, P. S. Balaram \& Sangisetti Manoj, "Political Empowerment of Women through Panchayats (A Study on Coastal Districts of Andhra Pradesh) “, BEST: International Journal of Management, Information Technology and Engineering (BEST: IJMITE), Vol. 3, Issue 9, pp. 47-52

14. Kwabena Owusu, "Corporate Governance and Internal Audit Challenges in a Decentralised Public Governance System in Ghana ", International Journal of Business and General Management (IJBGM), Vol. 7, Issue 6,pp. 17-30 


\section{AUTHORS PROFILE}

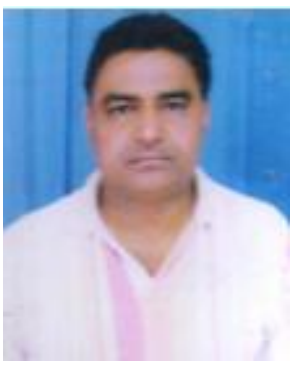

Dr. Kamal Kishore Pathak is currently working as a Lecturer (Selection Grade) at Government Polytechnic Sheikhpura (Bihar). He did his B.Sc. Engineering in Mechanical Engineering from Bihar College of Engineering, Patna in 1987. Since then he has been engaged in teaching and research. He obtained his M.Tech and Ph.D. from B.R.A. Bihar University, Muzaffarpur. He has wide exposure in the Mechanical Engineering field and has 30 years of experience in teaching engineering students. He is the life time member of Indian Society for Technical Education (ISTE) and also the author of the book "Strength of Materials (Mechanics of Solids)" ISBN: 978-8193003756, First Edition, Nexus Publication, Patna, 2017. 